\title{
Linguagens
}

\section{A LINGUAGEM NA CONSTRUÇÃO DE REPRESENTAÇÕES DE DEUS E DEMOCRACIA EM UMA VOTAÇÃO NA CÂMARA DOS DEPUTADOS}

\author{
Jéssica Cantele Freitas (UFSM) \\ Sara Regina Scotta Cabral (UFSM)
}

\begin{abstract}
RESUMO: Este trabalho tem por objetivo apresentar representações dos termos Deus e democracia pelas escolhas linguísticas de Deputados em seus votos na sessão que decidia a admissibilidade do impeachment de Dilma Rousseff. Tomou-se como base teórica a representação de atores sociais, de van Leeuwen (1997), e o Sistema de Transitividade, de Halliday e Matthiessen (2014). A pesquisa foi desenvolvida em seis etapas: descrição do contexto em que o corpus se insere; segmentação dos votos dos Deputados em orações e seleção das que possuíam os termos delimitados para análise; classificação pelo Sistema de Transitividade; classificação pela categoria de distribuição de papéis dos Atores Sociais; quantificação e categorização dos resultados; interpretação das evidências. Quanto aos atores sociais, verificou-se que Deus é representado ativamente $(64,5 \%)$ e democracia é representada passivamente $(78,4 \%)$. Sobre o sistema de transitividade, o participante Deus é representado como Receptor $(30,4 \%)$ e Ator $(26,0 \%)$, já democracia é realizada como Circunstância $(87 \%)$.
\end{abstract}

Palavras-chave: Representação. Atores sociais. Sistema de Transitividade. Discurso político.

\begin{abstract}
This paper aims to present representations of the terms God and democracy through the linguistic choices of Deputies/ Political in their votes in the session that decided the admissibility of the impeachment of Dilma Rousseff. The theoretical representation of social actors, van Leeuwen (1997), and the Transitivity System, by Halliday and Matthiessen (2014), were taken as theoretical basis. The research was developed in 6 steps: description of the context in which the corpus is inserted; Segmentation of Members' votes into clauses and selection of those who had the terms delimited for analysis; Classification by Transitivity System; Classification by category of distribution of roles of Social Actors; Quantification and categorization of results; Interpretation of the evidence. As for social actors, it was verified that God is actively represented (64.5\%) and democracy is represented passively (78.4\%). Regarding the system of transitivity, the participant God is represented as Receptor (30.4\%) and Actor (26.0\%), and democracy is performed as Circumstance (87\%).
\end{abstract}

Keywords: Representation. Social actors. Transitivity System. Political speech.

\section{INTRODUÇÃO}

Diferentes contextos de uso da linguagem vêm sendo objeto de estudo de diversas pesquisas que adotam a concepção de linguagem como prática social. No que concerne ao contexto político, relevantes pesquisas contribuem para os estudos dessa perspectiva teórica, tendo como foco os variados mecanismos disponíveis por ela para o estudo da linguagem, bem como fazendo uso dos inúmeros tipos de discurso desse âmbito contextual. Toma-se 


\section{S Linguagens}

como exemplo o estudo da modalidade em audiências públicas (BOCHETT, 2015), do uso do marcador não em discursos do ex-presidente Lula (CORRÊA, 2015) e de representações de participantes em discursos políticos (FREITAS, 2016a; 2016b).

Um evento comunicativo do contexto político pouco explorado em estudos linguísticos diz respeito às sessões de votação, em que os representantes do povo se reúnem para decidir, através de voto nominal, temas relativos a interesses públicos. No cenário político brasileiro, um acontecimento marcante, de grande repercussão no ano de 2016, referese ao processo de impeachment da ex-presidente Dilma Rousseff, caso esse que passou por sessões de votação na Câmara dos Deputados e no Senado Federal para que pudesse ser definido. Nesses eventos, diversos foram os argumentos utilizados pelos políticos para a justificativa de suas decisões, e alguns elementos foram recorrentes na defesa dos votos, o que lhes atribui caráter significativo.

Nesse sentido, objetiva-se, neste trabalho, evidenciar representações para os termos Deus e democracia nas falas dos políticos que participaram da primeira sessão de votação que decidia a admissibilidade do processo de impeachment da então presidente Dilma Rousseff, tomando como corpus de análise a transcrição da votação ocorrida em 17 de abril de 2016, na Câmara dos Deputados, disponível no site oficial dessa Casa (http://www2.camara.leg.br/). A escolha de investigação desses termos deu-se pelo fato de terem sido recorrentes nas falas dos votantes, além de apresentarem caráter controverso: uma entidade teocrática sendo invocada em um contexto político democrático.

A análise baseou-se nos preceitos teóricos da Linguística Sistêmico-Funcional, especificamente do Sistema de Transitividade da metafunção ideacional experiencial (HALLIDAY; MATTHIESSEN, 2014), que dá conta das representações das experiências no mundo, e pela representação dos Atores Sociais (VAN LEEUWEN, 1997), especificamente pela categoria de distribuição de papéis, que permite identificar a quem é atribuída a agência no que diz respeito a uma dada ação.

\section{PRESSUPOSTOS TEÓRICOS}




\section{S Linguagens}

A Linguística Sistêmico-Funcional, paradigma em que esta pesquisa está centrada, corresponde a uma teoria do funcionamento da linguagem humana que se baseia no uso linguístico. Nesse sentido, a linguagem é abordada em uma perspectiva sociossemiótica, na medida em que se trata de um sistema de significados, produzidos em um contexto social por meio de relações, constituindo a cultura humana (HALLIDAY; HASAN, 1985).

Dessa maneira, o uso da linguagem e das escolhas que se faz no sistema linguístico, nos mais diversos contextos, faz o sujeito constituir-se como um ser social, daí a importância fundamental que a linguagem possui no desenvolvimento do indivíduo. Conforme Halliday e Matthiessen (2014), “a linguagem é um recurso para fazer sentido, e o significado reside nos padrões sistêmicos de escolha" (p. 23).

A teoria sistêmica recebe esse nome visto que "a gramática de uma língua é representada sob a forma de redes de sistemas, e não como um inventário de estruturas" (HALLIDAY; MATTHIESSEN, 2014, p. 23). A linguagem, enquanto sistema, realiza sua materialização em textos e, nessa perspectiva,

o termo "texto" se refere a qualquer instância de linguagem, em qualquer meio, que faz sentido para alguém que conhece a linguagem; podemos caracterizar o texto como o funcionamento da linguagem em contexto. A linguagem é, em primeira instância, um recurso para fazer sentido; assim que o texto é um processo de fazer sentido no contexto. (HALLIDAY; MATTHIESSEN, 2014, p. 3).

Dessa maneira, o texto é compreendido como sendo uma unidade de sentido que serve para trocas sociais de significados em determinados contextos.

Nessa abordagem teórica, a noção de contexto possui papel primordial nos eventos linguísticos, pois se considera, segundo Halliday e Hasan (1985), que não existe um texto desvinculado de um ambiente de produção. Dessa maneira, compreende-se que o contexto "serve para fazer uma ponte entre o texto e a situação em que os textos realmente acontecem" (HALLIDAY; HASAN, 1985, p. 5). Na vida, os contextos precedem os textos, no sentido de que a situação é anterior ao discurso que diz respeito a ela, sendo relevantes, assim, a situação cultural de um texto e também o seu contexto imediato de produção, de modo que tenham sido cunhadas as concepções de contexto de cultura e de contexto de situação (HALLIDAY; HASAN, 1985). 


\section{Linguagens}

O contexto de cultura, dessa maneira, dá conta da história cultural de cada evento interativo, enquanto o contexto de situação refere-se à situação imediata de produção do texto; ambos desempenham papel na interpretação do significado. $O$ contexto de situação possui três variáveis distintas, que servem para interpretar o contexto social de um texto. A variável campo refere-se ao que está ocorrendo no momento; a variável relações diz respeito à natureza dos participantes, seus status e funções; por fim, a variável modo dá conta da organização simbólica do texto (HALLIDAY; HASAN, 1985).

Outra característica importante da Linguística Sistêmico-Funcional é atribuir três metafunções à linguagem, descritas por Halliday e Matthiessen (2004, 2014), as quais estão diretamente relacionadas às três variáveis citadas anteriormente. A metafunção ideacional relaciona-se com a variável campo do contexto de situação, responsável pela representação das experiências no mundo interior e exterior, sendo realizada pelo Sistema de Transitividade. A metafunção interpessoal é motivada pela variável relações, que é responsável pela interação dos participantes no discurso, sendo expressa pelo sistema de MODO. Por fim, a metafunção textual é relacionada à variável de modo, sendo responsável pela configuração dos significados das informações expressas (HALLIDAY; MATTHIESSEN, 2014).

Considerando que o propósito desta pesquisa é identificar as representações atribuídas aos termos Deus e democracia por Deputados Federais em suas falas, toma-se como foco de parte da análise a metafunção ideacional experiencial, pela qual "a linguagem fornece uma teoria da experiência humana" (HALLIDAY; MATTHIESSEN, 2014, p. 30), especificamente pelo seu Sistema de Transitividade.

Segundo Halliday e Matthiessen (2014), está-se no domínio da metafunção ideacional quando a linguagem é utilizada como forma de representação das experiências no mundo. Quando se analisa como os textos representam as pessoas, coisas e acontecimentos em um campo da atividade social, centra-se, conforme Halliday e Matthiessen (2014), na função experiencial, um dos domínios dessa metafunção da linguagem.

O sistema a que se refere essa metafunção é o de Transitividade, em que são compreendidas as ações, quem participa delas e em quais circunstâncias. Halliday e Matthiessen (2014) compreendem que a Transitividade é um sistema de relações que formam uma "figura", "uma configuração de elementos centrados num processo" (p. 213). Dessa 


\section{S Linguagens}

maneira, os autores dividem a oração em três componentes: processo, participantes e circunstâncias.

Desse modo, o processo é o elemento central da configuração, representado por grupos verbais; os participantes são as entidades envolvidas, textualizadas por grupos nominais, e as circunstâncias indicam o modo, o tempo, o lugar e a causa em que o processo acontece, sendo compostas por grupos adverbiais ou preposicionais. Cada oração possui seus participantes, e as circunstâncias podem permear todos os tipos de oração, mas o processo é o elemento central da configuração experiencial. Há seis tipos distintos de significados, o que resulta na classificação de seis tipos de orações: material, mental, relacional, verbal, comportamental ou existencial, dependendo do sentido que o processo exerce na oração.

Outro modo de atribuir representações aos participantes de um evento comunicativo, nessa abordagem teórica que considera a linguagem como prática social, diz respeito à perspectiva de representação de Atores Sociais, proposta por van Leeuwen (1997), que dá conta da estrutura utilizada pelo falante/escritor para a representação das experiências. Nessa perspectiva, há categorias sociossemânticas para o modo como os atores sociais são representados no discurso, tendo como categorias principais a Exclusão e Inclusão, as quais se subdividem em categorias mais específicas.

A categoria de Exclusão diz respeito a supressões ou encobrimento dos participantes do discurso, de modo que são utilizadas para servir os interesses e propósitos do escritor/falante em relação a quem o discurso se dirige, servindo para colocar determinados participantes em segundo plano. Quando o ator social é incluído no discurso, ou seja, quando não há supressão ou encobrimento dos participantes, as categorias atribuídas a ele podem ser: distribuição de papéis, atores sociais ou impersonalização $x$ personalização (VAN LEEUWEN, 1997).

No domínio deste trabalho, tendo como objetivo verificar se os termos delimitados para a análise foram representados como agentes nas falas dos Deputados, tomou-se como base a categoria de distribuição de papéis. Nessa categoria, de acordo com van Leeuwen (1997), as representações por ativação ocorrem quando os atores sociais são representados como forças ativas e dinâmicas numa atividade, podendo ser classificados por: participação, circunstancialização, pré-modificação, pós-modificação ou nominalizações; já as 


\section{S Linguagens}

representações por passivação ocorrem quando os atores sociais são representados como submetendo-se à atividade ou sendo receptor dela, podendo ser classificados por: sujeição, que, por sua vez, desdobra-se em participação, circunstancialização, possessivação ou prémodificação adjetival, ou por beneficialização, esta na categoria de participação.

Desse modo, partindo do nível léxico-gramatical com base no sistema de transitividade e em consonância com as características sociossemânticas da categoria de distribuição de papéis dos Atores Sociais, pretende-se identificar as representações construídas e manifestadas nas falas dos Deputados Federais para os termos Deus e democracia em situação de votação de um processo de impeachment de uma Presidente da República.

\section{METODOLOGIA}

Para a realização da análise pretendida, apresenta-se como corpus da pesquisa as falas que acompanharam os votos dos Deputados Federais na sessão que decidia a admissibilidade do processo de impeachment da Presidente Dilma Rousseff. A sessão de votação foi taquigrafada e traduzida, para, posteriormente, ser disponibilizada no site oficial da Câmara dos Deputados (http://www2.camara.leg.br/), local em que foi realizada a coleta do corpus.

A sessão transcrita é apresentada no endereço eletrônico supracitado contendo todos os momentos que configuraram a sessão de votação: sessão de abertura, esclarecimentos do Presidente da Câmara, fala do Relator, instruções para votação, discursos dos líderes dos partidos, votos individuais e encerramento. Para a análise, foi selecionada, a título de exemplificação, apenas a parte que se refere aos votos individuais, sendo coletados 511 votos ao total. No total de votos coletados, foi aplicado o critério de seleção daqueles que faziam referência direta aos termos delimitados para a análise. Dessa maneira, foi realizada busca pelos termos Deus e democracia em todos os votos, o que resultou em 139 votos ao total, sendo 46 que apresentavam o termo Deus e 93 que apresentavam o termo democracia. Cada exemplo recebeu uma numeração, constituída de sinal sustenido (\#) e seguidas dos números 1 a 139. Para a leitura da indicação dos exemplos, leia-se para \#48, por exemplo, "exemplo número $48 "$ constante na lista selecionada. 


\section{S Linguagens}

Para a análise dos textos, seis etapas foram adotadas:

1. Descrição do contexto de cultura e do contexto de situação em que o corpus está inserido;

2. Segmentação dos votos em orações e seleção das que possuíam os termos delimitados para análise;

3. Identificação dos componentes das orações selecionadas em participantes, processos e circunstâncias, de acordo com o Sistema de Transitividade;

4. Classificação dos termos delimitados para a análise pela categoria de distribuição de papéis de acordo com a perspectiva dos Atores Sociais;

5. Quantificação e categorização dos resultados;

6. Interpretação das evidências.

\section{ANÁLISE E DISCUSÃO DOS RESULTADOS}

Nesta seção, apresenta-se a análise contextual dos textos, bem como a análise pelo Sistema de Transitividade e pelos Atores Sociais dos termos Deus e democracia, a fim de verificar as suas representações no corpus selecionado.

\subsection{Descrição do contexto}

O contexto de cultura, conforme mencionado anteriormente, dá conta da história cultural de cada situação dos eventos interativos (HALLIDAY; HASAN, 1985). Nessa perspectiva, o contexto cultural que engloba a situação discursiva em que os participantes estavam inseridos é o país em que tudo ocorrera: Brasil, país republicano, cuja constituição prevê o direito de voto para decisão de afastamento de presidentes que não cumprirem com as responsabilidades a eles atribuídas.

A lei que regulamenta essa situação é a Lei $n^{\circ} 1.079$, de 10 de abril de 1950, a qual define os crimes de responsabilidade de um Presidente, bem como de Ministros, do Procurador Geral da República e de Governadores e Secretários de Estados, além de definir as condições do processo e do julgamento no caso de denúncia de improbidade administrativa de 


\section{S Linguagens}

algum gestor. No caso de denúncia contra um Presidente da República, atribui-se aos Deputados o direito de realizar votação individual para decidir a admissibilidade do processo:

Art. 23. Encerrada a discussão do parecer, será o mesmo submetido a votação nominal, não sendo permitidas, então, questões de ordem, nem encaminhamento de votação.

$\S 1^{\circ}$ Se da aprovação do parecer resultar a procedência da denúncia, considerar-se-á decretada a acusação pela Câmara dos Deputados. (BRASIL, LEI N ${ }^{\circ}$ $1.079 / 1950)$.

Nesse sentido, o encontro dos Deputados que deu origem à coleta do corpus utilizado nesta análise estava envolvido por um contexto maior: o contexto político brasileiro que segue uma Constituição, a qual assegura condições para a realização da votação naquele momento.

Já o contexto de situação refere-se à situação imediata da produção do texto, dando conta do que estava ocorrendo no momento do evento interativo. Conforme apresentado anteriormente, são três as variáveis do contexto de situação: campo, relações e modo (HALLIDAY; HASAN, 1985).

No caso do corpus selecionado para a análise, a variável campo, aquela que se refere ao que está ocorrendo no momento, trata-se, conforme já mencionado, de uma sessão de votação em que Deputados deveriam optar por "sim", "não" ou "abstenção" em relação ao prosseguimento do processo de impeachment da Presidente da República Dilma Rousseff, apresentando as justificativas de votos.

No que se refere à variável relações, aquela que diz respeito à natureza dos participantes, inclui-se, nessa ocasião de votação, o então Presidente da Câmara dos Deputados, Eduardo Cunha, que comandava a sessão, e 511 Deputados Federais de todos os partidos do território Nacional.

Por fim, a variável modo do contexto de situação, que trata da organização simbólica do texto, refere-se, inicialmente, ao modo oral, tendo sido realizado com o uso de microfone e televisionado para o mundo no momento imediato da situação interativa, enquanto os Deputados realizavam seus votos. Porém, para a realização da análise, o corpus selecionado, inicialmente oral, passou para o modo escrito por meio de escuta, taquigrafia e tradução, sendo disponibilizado na página virtual da Câmara dos Deputados (www2.camara.leg.br), onde foi coletado para a análise. Os votos constituem-se conforme exposto no exemplo 1: 


\section{Linguagens}

\begin{tabular}{|l|l|l|l|}
\hline x.1 & $\begin{array}{l}\text { O SR. ZECA DIRCEU (PT-PR.) - Meu voto será uma homenagem aos } \\
\text { jovens da década de 60, que lutaram contra a ditadura (palmas), uma homenagem } \\
\text { aos jovens que, há muitos meses, estão nas ruas, lutando contra esse golpe, uma } \\
\text { homenagem aos sindicalistas, aos movimentos sociais, a todos aqueles que sabem } \\
\text { que o que está em jogo não é apenas um Governo, não é apenas a figura da } \\
\text { Presidenta Dilma, é a democracia. } \\
\text { Meu voto é não. (Palmas.) }\end{array}$ & $\mathbf{1 1 1}$ & \\
\hline
\end{tabular}

Percebe-se, no exemplo acima, que antes da apresentação das falas dos Deputados há a presença do nome do votante, bem como a identificação do partido e o estado a que pertence. Posteriormente, há a transcrição da justificativa e do voto, sendo apresentadas, também, as manifestações dos demais presentes na sessão de votação, destacadas em itálico, como palmas no exemplo 1.

\subsection{Representações para o termo "Deus"}

O termo Deus foi mencionado por 46 Deputados em suas justificativas de votos. No que se refere à análise do Sistema de Transitividade nas orações que apresentavam o termo Deus, constatou-se uma predominância significativa de processos verbais e processos materiais (Figura 1).

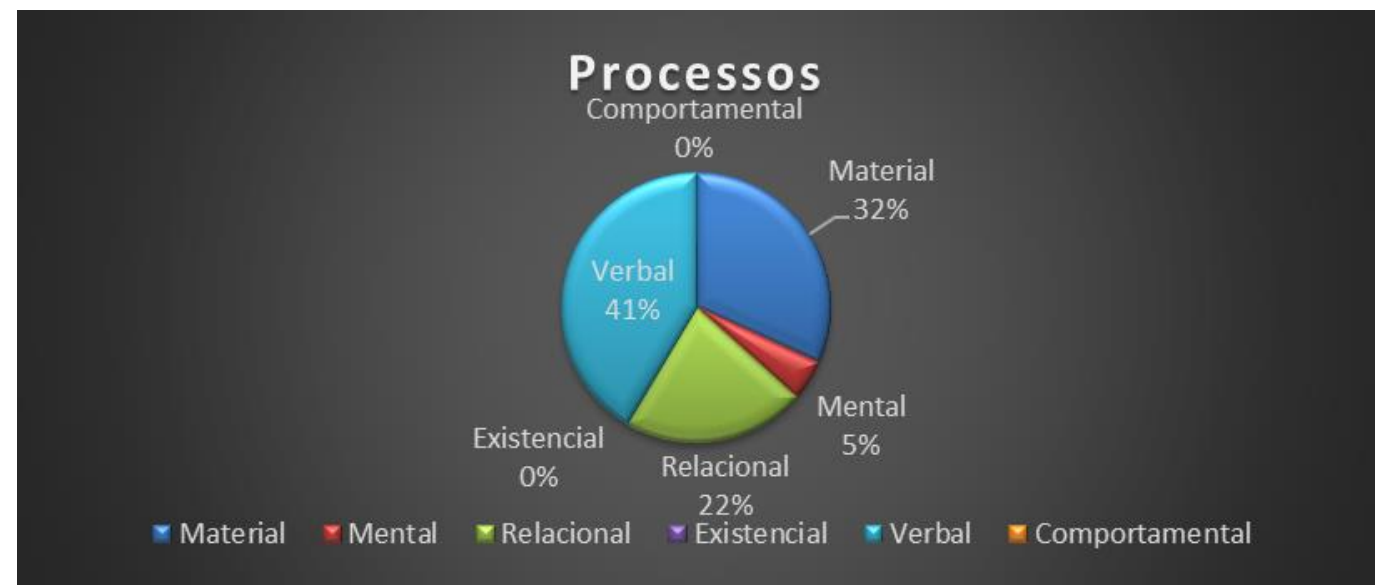

Figura 1: Porcentagem dos processos utilizados em orações referentes a Deus. Fonte: as autoras 


\section{Singuagens}

Quanto à função do participante Deus nas orações que utilizam processos de dizer (verbais) e de fazer e acontecer (materiais), verificou-se que os papéis desempenhados por ele eram predominantemente de Receptor (30,4\%) nos processos verbais (ex. 2) e de Ator (26\%) nos processos materiais (ex. 3).

\begin{tabular}{|l|l|l|}
\hline Ex. 2 & $\begin{array}{l}\text { Gostaria, em primeiro lugar, de agradecer a Deus por este momento e pedir- } \\
\text { lhe misericórdia para nossa nação. }\end{array}$ & \#123 \\
\hline
\end{tabular}

\begin{tabular}{l|l} 
Ex. 3 & Que Deus abençoe o nosso país nesse momento tão difícil.
\end{tabular}

Verifica-se, no exemplo 2, que, com o uso dos processos verbais agradecer e pedir, os falantes possibilitam entrever um papel relevante a Deus na situação em questão, pois, ao atribuir-lhe caráter de participante Receptor dos discursos, os Deputados dirigem a mensagem a essa entidade espiritual, de modo que atribuem a ela participação direta no processo em discussão no momento.

No exemplo 3, nota-se que, com o uso do processo material abençoar, os Deputados atribuem a Deus o papel de participante Ator, de modo que Ele seja compreendido como uma entidade que possui influência para a resolução da situação que estava sendo discutida, pois, ao ser representado como esse participante, os falantes Lhe dão o caráter de agente, ou seja, Aquele que realiza a ação e que desenvolve o processo.

No que concerne à análise dos Atores Sociais, foi possível constatar que Deus foi predominantemente representado pela categoria de ativação, que dá conta da representação dos atores sociais como forças dinâmicas nas atividades (Figura 2). 


\section{Linguagens \& Cidadania}

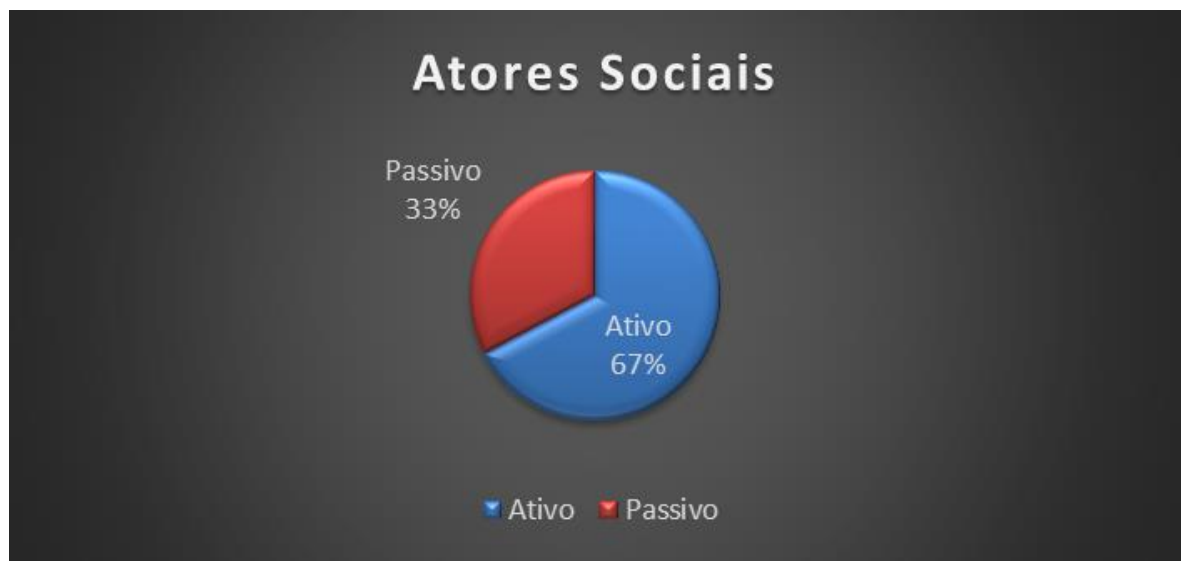

Figura 2: Porcentagem das categorias dos Atores Sociais referentes a Deus.

Fonte: as autoras

Dentro dessa categoria predominantemente utilizada, verificou-se a recorrência da utilização da subcategoria participação (72\%), a qual atribui ao termo Deus um papel ativo e mais destacado na oração (ex. 4).

\begin{tabular}{|l|l|l|}
\hline Ex. 4 & $\begin{array}{l}\text { Sr. Presidente, que a partir de amanhã, segunda-feira, Deus possa derramar muitas } \\
\text { bênçãos sobre o nosso Brasil e sobre o povo brasileiro. }\end{array}$ & $\# \mathbf{1}$ \\
\hline
\end{tabular}

Verifica-se, no exemplo 4, que é conferido a Deus o status de agente da atividade, possuindo participação na ação para auxiliar o povo brasileiro em decorrência da instabilidade do momento político em que o país estava vivendo. Assim, é possível verificar aqui, também, uma ênfase maior dada a essa entidade, de maneira que os Deputados atribuem a ela, e não a eles, o foco da ação.

\subsection{Representações para o termo "Democracia"}

Do total de votos, conforme citado anteriormente, 93 deles apresentaram o termo democracia na justificativa. No que concerne à análise do Sistema de Transitividade nessas orações, verificou-se a predominância de processos materiais, seguido por processos relacionais (Figura 3). 


\section{Linguagens \& Cidadania}

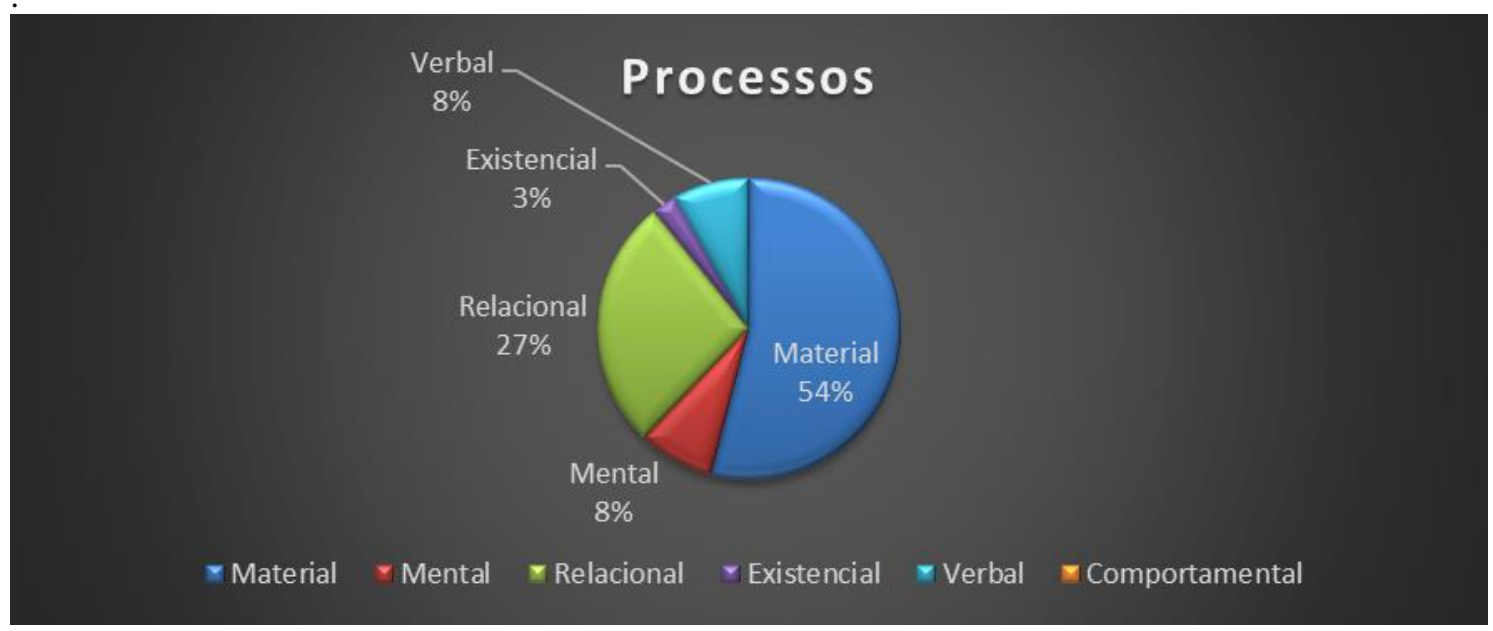

Figura 3: Porcentagem dos processos utilizados em orações referentes a Deus Fonte: as autoras

Entretanto, apesar da predominância dos processos de fazer (materiais) e de caracterizar (relacionais), o que ganha destaque, aqui, é a recorrência do uso do termo democracia não como participante, mas em forma de circunstância. $\mathrm{O}$ uso desse termo como circunstância representa $87 \%$ das vezes que ele é apresentado pelos Deputados (ex. 5), ou seja, representa um número muito maior do que as vezes que esse termo se constitui enquanto oração.

\begin{tabular}{|l|l|l|}
\hline Ex. 5 & Em defesa da democracia, voto não ao golpe. & $\mathbf{\# 2 7 0}$
\end{tabular}

Nesse sentido, percebe-se que, ao empregar o termo democracia por meio de circunstância, os Deputados contextualizam a justificativa do voto, não sendo atribuído status de participante. Além disso, enquanto circunstância, o papel do termo passa a ser secundário, visto que faz parte de uma oração menor.

Quanto à análise dos Atores Sociais, foi possível identificar que democracia foi predominantemente representada pela categoria de passivação, que trata de atores sociais que se submetem à atividade ou são receptores dela (Figura 4). 


\section{Linguagens \& Cidadania}

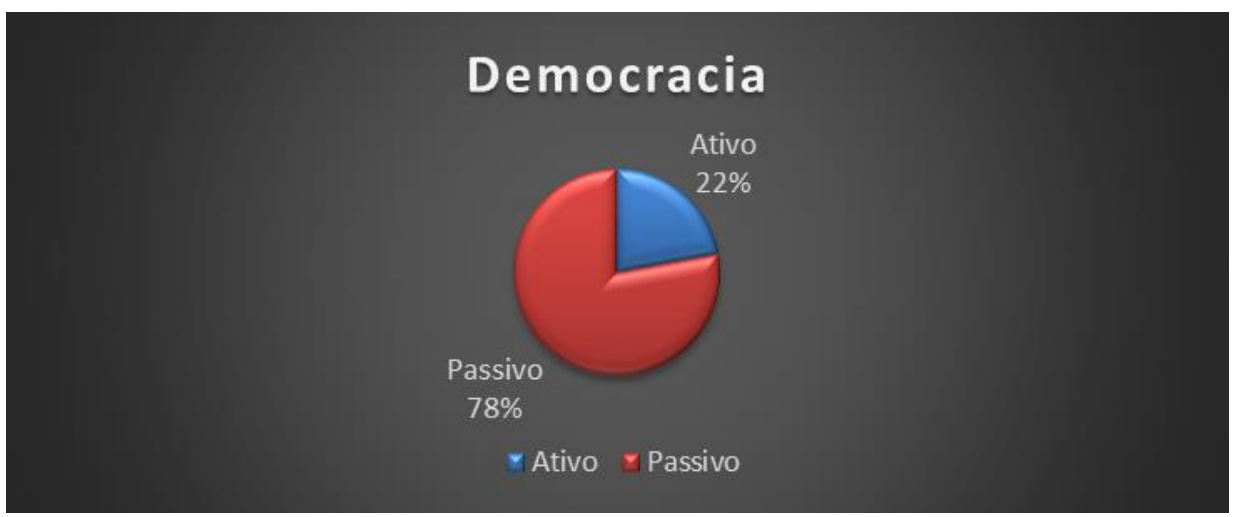

Figura 4: Porcentagem das categorias dos Atores Sociais referentes a Deus.

Fonte: as autoras

Dentro dessa categoria, predominantemente utilizada, verificou-se a significativa recorrência da subcategoria de beneficialização (87\%), que atribui ao termo democracia um status de beneficiado pela ação (ex. 6).

\begin{tabular}{|l|l|l|}
\hline Ex. 6 & $\begin{array}{l}\text { Pela democracia, em respeito à Constituição, que juramos cumprir nesta } \\
\text { Casa, pela cidadania dos mais pobres deste País, o meu voto é não! }\end{array}$ & $\# 85$ \\
\hline
\end{tabular}

Dessa maneira, no exemplo 6, é possível identificar que democracia está sendo beneficiada pela situação de voto, ou seja, ela não age, ela recebe a ação dos outros. Assim, verifica-se que a democracia não possui caráter ativo na situação de decisão do futuro político de um Estado democrático, sendo reservada a ela a função de "homenageada" na sessão.

\section{CONSIDERAÇÕES FINAIS}

A partir da análise realizada, pode-se constatar que ambas as categorias utilizadas para análise - Sistema de Transitividade e Atores Sociais - indicam representações semelhantes para cada um dos termos delimitados para este estudo.

Pelo emprego do Sistema de Transitividade pode-se concluir que, nas falas dos Deputados que utilizaram o termo Deus, essa entidade foi compreendida como tendo papel 


\section{S Linguagens}

principal no ato em questão, pois, como Receptor, os Deputados dirigiam o voto a ela, ou, enquanto Ator, conferiam a ela a responsabilidade pela escolha do voto.

Já em relação a democracia, ainda na análise pelo Sistema de Transitividade, verificou-se que esta exerceu papel menor, uma vez que, na condição de circunstância, deixou de ser o centro da oração.

Já no que se refere à análise das orações pela categoria de Distribuição de Papéis, da representação dos Atores Sociais, a partir das evidências, é possível concluir que Deus é representado como um ator participativo, que tem status de iniciador da atividade em questão. Diferentemente, verificou-se que, ainda nessa categoria, democracia é tratada como um participante passivo, de modo que os Deputados a representam com status de beneficiado pela situação.

Conclui-se, dessa maneira, que, em ambas as categorias de análise, Deus é representado como um ator participativo e democracia como participante Beneficiário. As falas dos Deputados deixam entrever, desse modo, uma entidade espiritual, teocrática e atuante, que lhes inspira o voto diante de todos, e outra, de caráter institucional, em nome da qual esse voto seria - e foi - proferido.

\section{REFERÊNCIAS}

BOCHETT, A. C. Modalidade em discursos ambientalistas: jogos de máscaras em gêneros que compõem as audiências públicas. Dissertação (mestrado) - Universidade Federal de Santa Maria, Centro de Artes e Letras, Programa de Pós-Graduação em Letras, RS, 2015.

BRASIL. Define os crimes de responsabilidade e regula o respectivo processo de julgamento, Lei $\mathrm{n}^{\circ}$ 1.079, 10 de abril de 1950. Disponível em: http://www2.camara.leg.br/legin/fed/lei/1950-1959/lei-1079-10-abril-1950-363423normaatualizada-pl.pdf. Acesso em: 01/07/2016.

CORRÊA, E. K. C. Discurso político de Lula: o papel do marcador político "não" na construção da persona textual. Dissertação (mestrado) - Universidade Federal de Santa Maria, Centro de Artes e Letras, Programa de Pós-Graduação em Letras, RS, 2015.

FREITAS, J. C. Teocracia x Democracia em uma votação na Câmara dos Deputados. In: CÍRCULO DE ESTUDOS LINGUÍSTICOS DO SUL, 12, 2016, Santa Maria. Anais... Santa 


\section{Linguagens L \& Cidadania}

Maria: UFSM, 2016a. Disponível em:

<http://celsul2016.ufsm.br/images/ebook_celsul_270916.pdf>. Acesso em: 20 set. 2016a.

FREITAS, J. C. Teocracia em Tempos de Democracia. In: JORNADA ACADÊMICA INTEGRADA, 31, 2016, Santa Maria. Anais... Santa Maria: UFSM, 2016b. Disponível em: <https://portal.ufsm.br/jai/anais/trabalho.html?action=anais>. Acesso em: 10 nov. $2016 \mathrm{~b}$.

HALLIDAY, M. A. K.; HASSAN, R. Language, Context and Text: aspects of language in a social-semiotic perspective. Oxford: Oxford University Press, 1985.

HALLIDAY, M. A. K.; MATTHIESSEN, C. M. I. M. Halliday's Introduction to

Functional Grammar. New York / London: Routledge, 2014.

PORTAL da Câmara Dos Deputados. Disponível em: http://www2.camara.leg.br/. Acesso em: 1 de junho de 2016.

VAN LEEUWEN. A representação dos actores sociais. In: PEDRO, E. R. (Org.). Análise Crítica do Discurso. Lisboa: Caminho, 1997. p. 169-222. 